LIAMES, Campinas, SP, v. 20, 1-23, e020006, 2020

\title{
Evaluación del estado de desplazamiento del zapoteco en Juchitán de Zaragoza, México
}

\author{
Roberto Guerra-Mejía \\ Universidad Nacional Autónoma de México, México \\ https://orcid.org/0000-0003-0127-8138
}

\begin{abstract}
The objective of this study is to evaluate the degree of Zapotec language shift in the city of Juchitán de Zaragoza, Oaxaca, Mexico. This research is based on the ecology of pressures theory. This theory suggests that in a language contact situation, there are negative pressures, caused by asymmetric relationships of power, that leads speakers to act against the vitality of the local language. In this work, a descriptive study of Juchitán's societal bilingualism is carried out for identifying the inhabitants' linguistic skills in Zapotec and in Spanish, as well as the changes of both languages through generations. For data collection, a survey was applied to a sample of 382 people of a total of 74825 inhabitants. During survey process, the participants were asked to make a self-assessment of their Zapotec and Spanish communicative competence. The results showed that the number of Zapotec speakers is intergenerationally decreasing. This is observed in the fact that most children are Spanish monolinguals and very few of them can only understand Zapotec. In contrast, people of all ages have developed high linguistic skills in Spanish. In conclusion, Zapotec language shift is advanced in Juchitán community.

KEYWORDS: Zapotec and Spanish; Language shift; Ecology of pressures; Common routine; Utmost common routine.
\end{abstract}

RESUMEN: El objetivo de este estudio es evaluar el grado de desplazamiento lingüístico que presenta el zapoteco en la ciudad de Juchitán de Zaragoza, Oaxaca, México. Este trabajo se enmarca en la teoría de ecología de presiones, la cual indica que, en una situación de contacto lingüístico, existen relaciones asimétricas de poder que generan presiones negativas hacia los hablantes de la lengua autóctona, llevándolos a actuar en contra de la vitalidad de su propia lengua. En este estudio se realiza un análisis descriptivo del bilingüismo social de la comunidad de Juchitán con el propósito de identificar las habilidades lingüísticas de los habitantes en zapoteco y en español, así como los cambios que ambas lenguas han tenido intergeneracionalmente. La recolección de datos se realizó por medio de un cuestionario aplicado a una muestra de la población de 382 personas de un total de 74825 habitantes. Durante este procedimiento, a los encuestados se les solicitó que evaluaran su nivel de competencia comunicativa tanto en zapoteco como en español. Los resultados muestran que el zapoteco presenta una reducción considerable de su transmisión intergeneracional, lo que se observa en el hecho de que la mayoría de los niños son hablantes monolingües del español y solo un número reducido de ellos puede entender el zapoteco. En contraste, el español se ha consolidado en todos los grupos generacionales, aún entre los adultos mayores. Debido a esto, se concluye que el zapoteco presenta un estado avanzado de desplazamiento lingüístico en la comunidad de Juchitán.

PALABRAS CLAVE: Zapoteco y español; Desplazamiento lingüístico; Ecología de presiones; Facilidad compartida; Máxima facilidad compartida. 
Introducción

México es un país con una amplia diversidad de lenguas indígenas, compuesta por 11 familias lingüísticas, 68 agrupaciones lingüísticas y 364 variantes lingüísticas (Instituto Nacional de Lenguas Indígenas [INALI] 2009: 32-37). Sin embargo, actualmente se estima que todas las lenguas indígenas mexicanas se encuentran en menor o mayor grado en peligro de extinción como consecuencia de un proceso de desplazamiento lingüístico provocado por el español. ${ }^{1}$

El INALI (2012: 16-18) indica que, de las 364 variantes lingüísticas que existen en el territorio mexicano, 64 están consideras con muy alto riesgo de desaparición, 43 con alto riesgo, 72 con riesgo medio y 185 con riesgo no inmediato. Asimismo, el Instituto Nacional de Estadística y Geografía (INEGI 2015) informa que solo 6.5\% de los 113294 340 mexicanos que cuentan con 3 años y más hablan alguna lengua indígena. ${ }^{2}$

El presente estudio analiza la vitalidad del zapoteco, variante de la planicie costera, en la localidad de Juchitán de Zaragoza, ubicada en el estado de Oaxaca, al sureste de México. Por mucho tiempo, el zapoteco en esta comunidad fue referencia de un caso exitoso de mantenimiento de una lengua indígena en un contexto de urbano, pero en los últimos tiempos existe una percepción generalizada entre la población de que el zapoteco se extingue; debido principalmente a que las generaciones más jóvenes ya no hablan la lengua y a que sus ámbitos tradicionales de uso se han reducido considerablemente.

Aunque diversas instancias coinciden en que el zapoteco de la planicie costera tiene una vitalidad estable, este diagnóstico no se ajusta a la situación sociolingüística de la comunidad de Juchitán; en parte porque son evaluaciones generales del conjunto de comunidades que hablan la lengua. Además, hay indicios que señalan que el zapoteco presenta un mayor peligro de extinción en la comunidad de Juchitán.

El objetivo de esta investigación es evaluar el estado actual de desplazamiento lingüístico que presenta el zapoteco intergeneracionalmente en la población de Juchitán. Para ello, se realiza un estudio descriptivo del bilingüismo social de la comunidad; esto es, se identifican y se comparan las habilidades lingüísticas de los diferentes grupos generacionales tanto en zapoteco como en español.

Este estudio toma como base la teoría de ecología de presiones (Terborg 2006; Terborg y García Landa 2011), la cual sugiere que las acciones de los hablantes de las lenguas en contacto están influenciadas por presiones, producidas por las relaciones asimétricas de poder que existen entre los hablantes. Esta teoría además explica cómo las presiones dictan la lengua que los interlocutores elegirán durante el desarrollo de sus interacciones comunicativas.

Este artículo está integrado por siete secciones. La sección 1 ilustra la situación sociolingüística de la comunidad de Juchitán. La sección 2 provee un marco conceptual

${ }^{1}$ El INALI es un organismo descentralizado del Estado mexicano cuyo objetivo es promover el fortalecimiento, preservación y desarrollo de las lenguas indígenas que se hablan en el territorio nacional, así como el conocimiento y disfrute de la riqueza cultural de la nación, y asesorar a los tres órdenes de gobierno para articular las políticas públicas necesarias en la materia.

${ }^{2}$ El INEGI es un instituto autónomo del Estado mexicano, que se encarga de producir, integrar y dar a conocer la información estadística (de la población y la economía) y geográfica (abarca todos los aspectos que caracterizan el territorio de México). 
sobre el desplazamiento lingüístico. La sección 3 presenta los antecedentes de la investigación. La sección 4 explica la teoría de ecología de presiones. La sección 5 describe diseño metodológico. La sección 6 muestra los resultados obtenidos de la evaluación del estado de desplazamiento del zapoteco. Finalmente, la sección 7 brinda las conclusiones y reflexiones del estudio.

\section{Contexto sociolingüístico}

La localidad de Juchitán de Zaragoza, cabecera del municipio del mismo nombre, está ubicada en la región del Istmo de Tehuantepec del estado de Oaxaca, al sureste de México (véase Figura 1). Juchitán es una localidad urbana con un grado medio de marginación, que cuenta con 74825 habitantes, $48.4 \%$ son hombres y $51.6 \%$ mujeres (INEGI 2010).

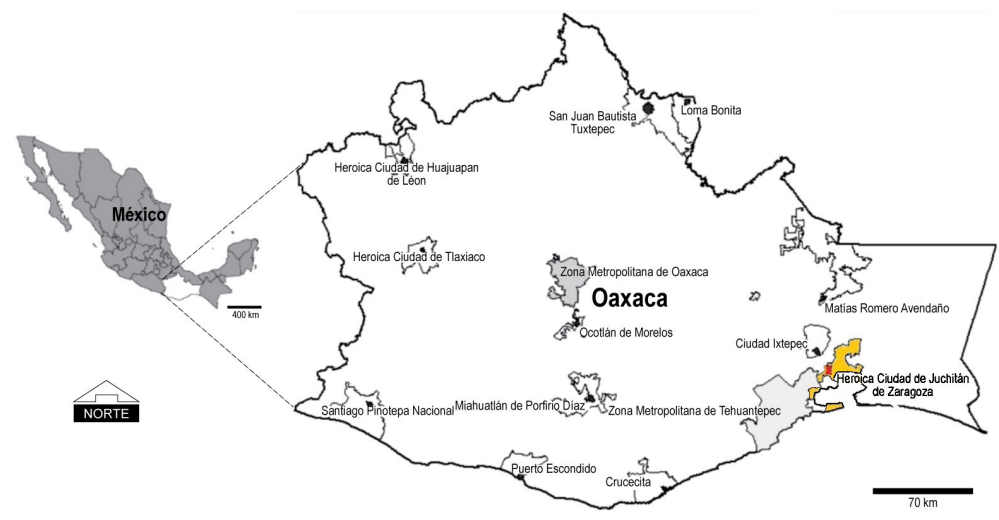

Figura 1: Ubicación geográfica de Juchitán de Zaragoza Nota. Adaptado de Miguel-Velasco et al. (2017: 530).

Respecto a su composición étnica, el Instituto Nacional de los Pueblos Indígenas (INPI 2010 ) indica que $86.5 \%$ de los habitantes se reconocen como indígenas. Esta característica hace distintiva a Juchitán, ya que se suele pensar que los centros urbanos concentran un número reducido de población autóctona. ${ }^{3}$

Tradicionalmente, los juchitecos han hablado la lengua zapoteca, variante de la planicie costera; sin embargo, en la actualidad el español se ha posicionado como la lengua mayoritaria de la comunidad. El INEGI (2010) reporta que 61.7\% de los 70506 habitantes de 3 años y más hablaban zapoteco, de los cuales $6.1 \%$ son monolingües y $92.8 \%$ bilingües zapoteco-español.

${ }^{3}$ El INPI es la instancia del Gobierno de México, que tiene como objeto definir, normar, diseñar, establecer, ejecutar, orientar, coordinar, promover, dar seguimiento y evaluar las políticas, programas, proyectos, estrategias y acciones públicas, para garantizar el ejercicio y la implementación de los derechos de los pueblos indígenas y afromexicano, así como su desarrollo integral y sostenible y el fortalecimiento de sus culturas e identidades. 
Con relación a la actividad econónomica de la población, los juchitecos son ampliamente conocidos por mantener una economia activa y sustentable en la región del Istmo de Tehuantepec, a pesar de que no existe ningún tipo de industria manufacturera ni desarrollo turístico, siendo las actividades comerciales las principales fuentes de empleo; igualmente, todavía hay un sector de la población que realiza actividades relacionadas con la artesanía, la pesca, la agricultura y la ganadería.

A diferencia de otras comunidades urbanas de la región, los habitantes de Juchitán han mostrado un mayor mantenimiento de la lengua e identidad indígena, aunque en los últimos tiempos han adoptado estilos de vida más vanguardistas. Se puede decir que los juchitecos han sabido, hasta cierto punto, combinar y adaptar su cultura a las necesidades del mundo moderno.

\section{Conceptos generales del desplazamiento lingüístico}

De acuerdo con Crystal (2000: 1-2), una lengua muere cuando ya nadie más la habla, aun cuando haya registros documentales de la lengua si no existen hablantes fluidos-vista como una herramienta de comunicación- está prácticamente muerta. Campbell y Muntzel (1989: 182-186) distinguen cuatro tipos de muerte de lenguas: a) muerte súbita, se da por aniquilación de la población o enfermedades, no hay una etapa previa de bilingüismo; b) muerte radical, los hablantes dejan de hablar su lengua, como una estrategia de supervivencia; c) muerte gradual, se genera cuando una lengua es gradualmente remplazada por otra, hay etapas previas de bilingüismo; d) muerte de abajo hacia arriba, la lengua deja de usarse en ámbitos privados, pero sobrevive en situaciones religiosas o en canciones populares, entre otras.

Con base en lo anterior, podemos observar que las lenguas pueden morir de forma progresiva o acelerada, que en la mayoría de los casos se produce progresivamente a través de varias generaciones como efecto de un contacto entre lenguas y conforme su avance, se hablará de lenguas moribundas u obsoletas cuando la muerte parezca ser inminente, de lo contrario, se tratará de lenguas amenazadas o en peligro de extinción (Craig 1998: 259).

El contacto lingüístico o de lenguas se origina cuando dos comunidades con distintas lenguas se encuentran y coexisten en un mismo territorio, lo que es causado por motivos migratorios o colonizadores. Como resultado de este encuentro, en la nueva comunidad lingüística existen dos lenguas: la lengua autóctona $\left(\mathrm{L}_{1}\right)$ y la lengua importada $\left(\mathrm{L}_{2}\right)$. Entonces, se entiende que dos lenguas están en contacto si ambas son habladas en una misma sociedad, al menos por un sector de la población; en otras palabras, cuando en una comunidad existe bilingüismo social.

Este último concepto, hace referencia a que en una comunidad bilingüe puede existir individuos monolingües en $L_{1}$, monolingües en $L_{2}$ y bilingües en $L_{1}$ y en $L_{2}$ (Rojo Sánchez 1981: 269-270). Sin embargo, este bilingüismo social se da de forma asimétrica, lo que provoca que una lengua sea vista como minoritaria, generalmente la $L_{1}$, y la otra como mayoritaria, la $\mathrm{L}_{2}$. Esto se debe a que suele haber más hablantes monolingües en la lengua mayoritaria y muy pocos en la lengua minoritaria; además, los hablantes bilingües generalmente desarrollan una alta competencia en la lengua mayoritaria, pero presentan 
distintos niveles de competencia en la lengua minoritaria que va da la plena competencia a la competencia mínima.

Las situaciones de contacto de lenguas implican, además de factores lingüísticos, situaciones sociales de carácter cultural, ideológico, político, económico o simbólico, por lo que en ocasiones se puede generar una situación conflictiva en la que los hablantes de los dos sistemas lingüísticos compiten entre sí provocando el desplazamiento total o parcial de una de las lenguas. En este caso, cabría hablar de la existencia de un verdadero conflicto lingüístico, que conlleva condiciones de desigualdad social entre las lenguas (Ninyoles 1969). Dada estas relaciones inequitativas, también se puede hablar de lenguas minorizadas y dominantes.

Durante un conflicto lingüístico, el uso de lengua minorizada es coartado en la sociedad, mientras que el de la lengua dominante, al ostentar el poder hegemónico, es ampliamente promovido. Es importante mencionar que la lengua minoritaria tiende también a ser la lengua minorizada, aunque no siempre es así (Bastardas-Boada 2016: 451-452).

Todas estas condiciones desiguales son motores del desplazamiento de la lengua autóctona, que se manifiesta de diversas formas, restructurando durante su evolución el entorno sociolingüístico de la comunidad.

Por un lado, Fishman (1991: 1) indica que una comunidad lingüística ve amenazada la vitalidad de su lengua local como consecuencia de una disminución de su transmisión intergeneracional; esto se refiere a que cada vez la lengua tiene menos usuarios o usos en cada generación. Entonces, el desplazamiento lingüístico puede ser visto como la pérdida de habilidades lingüísticas entre generaciones (de Bot 1996: 579, citado por SmithKocamanhhul 2003: 3), que se observa, según Craig (1998: 259), en el hecho de que una lengua amenazada cuenta con un rango de hablantes que va de hablantes fluidos, generalmente personas mayores, a hablantes receptivos, en su mayoría jóvenes que solo entienden la lengua, a los que se les denomina hablantes en fase terminal; en las generaciones intermedias es posible encontrar hablantes semifluidos que han desarrollado buenas habilidades de comprensión, pero presentan habilidades de producción limitadas (Grinevald y Bert 2011: 50).

Por otra parte, Zimmermann (1999) considera que el desplazamiento lingüístico "es un desplazamiento de las funciones de una lengua, es decir el desuso paulatino en dominios sociales" (p. 113), que se produce como efecto de un bilingüismo social diglósico (Fishman 1967), en donde la lengua dominante es considerada la lengua de mayor prestigio, por tanto, es utilizada en ámbitos oficiales y públicos, en tanto que el uso de la lengua autóctona se restringe a ámbitos privados, como la familia. Si bien esta situación diglósica, hasta cierto punto estable, ejerce una presión constante para ir desplazando a la lengua autóctona de los ámbitos que aún conserve.

En un proceso de desplazamiento lingüístico una comunidad lingüística atraviesa por una transición progresiva de un bilingüismo social inestable a un monolingüismo en la lengua mayoritaria o dominante, que se desarrolla hasta en cinco etapas: 1) monolingüismo relativo en la $\mathrm{L}_{1}, 2$ ) bilingüismo con predominancia en $\mathrm{la}_{1}, 3$ ) bilingüismo con predominancia en la $\mathrm{L}_{2}$, 4) uso restringido de la $\mathrm{L}_{1}$, y 5) la $\mathrm{L}_{1}$ como un sustrato, a este nivel la $\mathrm{L}_{1}$ está muerta (Batibo 2005: 90-92). Cuando este proceso concluye, según Fasold 
(1996: 321), se puede decir que una comunidad ha abandonado totalmente su lengua en beneficio de otra.

\section{Antecedentes}

\subsection{Vitalidad del zapoteco de la planicie costera}

El zapoteco de la planicie costera, también conocido como diidxazá, es una de las 62 variante lingüísticas que conforman el grupo lingüístico zapoteco, perteneciente a la familia lingüística oto-mangue. Esta variante lingüística es la lengua de la etnia zapoteca, autodenominados binnizá, quienes habitan en 23 municipios de la región del Istmo de Tehuantepec (cf. Figura 2). ${ }^{4}$

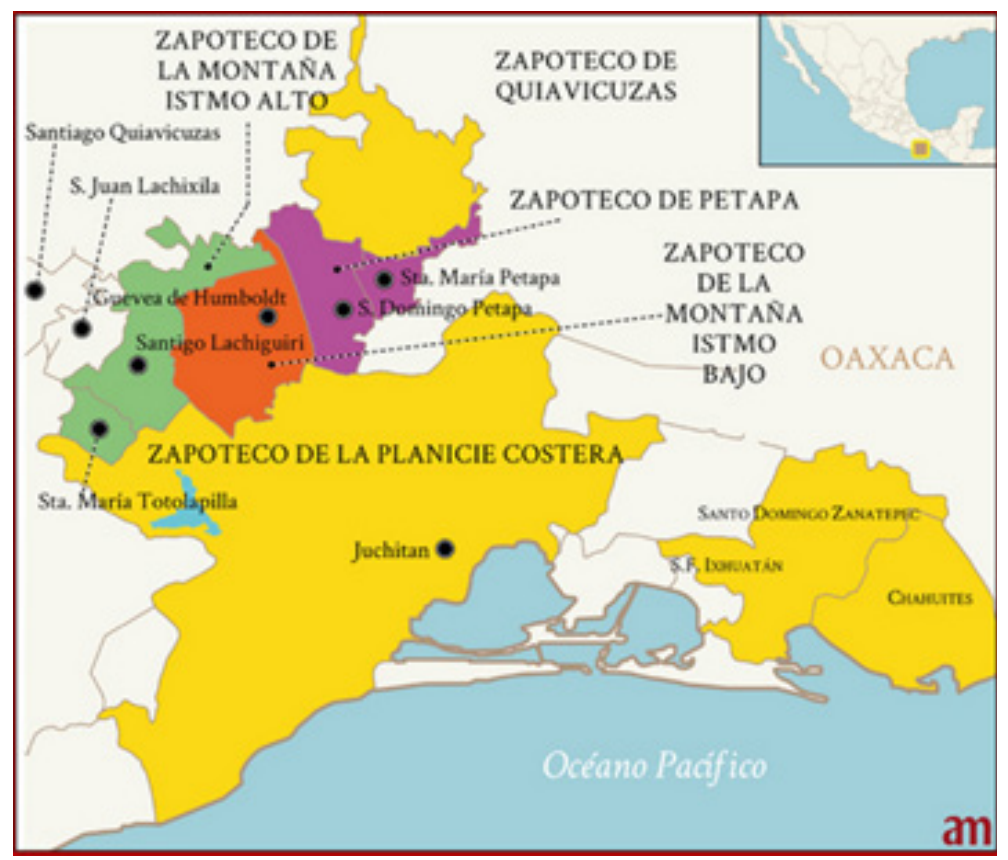

Figura 2: Ubicación geográfica del zapoteco de la planicie costera Nota. Tomado de Valiñas Coalla (2019: 78).

Se estima que en la región del Istmo de Tehuantepec el contacto lingüístico entre el zapoteco y el español se suscitó a inicios del siglo XVI, aproximadamente en 1521. Desde ese entonces, comenzó el conflicto lingüístico entre ambas lenguas. Esta situación

${ }^{4}$ En el Catálogo de las Lenguas Indígenas Nacionales (INALI 2009) se nombra a esta variante lingüística como zapoteco de la planicie costera, aunque tradicionalmente se ha empleado el nombre de zapoteco del Istmo o zapoteco de Juchitán. La UNESCO y Ethnologue emplean el nombre zapoteco del Istmo. 
ha provocado que el zapoteco haya sufrido una serie de cambios no solo en su estructura lingüística, sino también en su estructura social.

Dicho conflicto ha causado en las comunidades zapotecas un bilingüismo social diglósico, que ha puesto al zapoteco en condiciones sociales inequitativas frente al español. Por lo que no es de sorprender que el español sirva como medio de comunicación en ámbitos sociales de mayor prestigio como el gobierno, el mercado de empleo formal, los medios de comunicación y el sistema educativo, lo que atenta en contra de la vitalidad del zapoteco.

Al respecto, el INALI (2012: 43) clasifica el grado de peligro de desaparición del zapoteco de la planicie costera con riesgo medio, debido a que cuenta con 101593 hablantes, de los cuales $18.47 \%$ son niños entre 5 y 14 años; además, en $58 \%$ de las 343 localidades en donde está presente, los hablantes del zapoteco representan $30 \%$ y más de la población. Por otra parte, la Organización de las Naciones Unidas para la Educación, la Ciencia y la Cultura (UNESCO) en su publicación Atlas de las lenguas del mundo en peligro (Moseley 2010), evalúa la vitalidad de esta variante lingüística como vulnerable, esto se refiere a que la mayoría de los niños hablan la lengua, pero su uso puede estar restringido a determinados ámbitos como el hogar. Asimismo, en Ethnologue (Eberhard; Simons y Fennig 2020), se clasifica el estatus del zapoteco como en desarrollo, es decir, la lengua tiene un uso vigoroso en la comunidad lingüística, con una literatura estandarizada, aunque no generalizada en la población.

No obstante, gracias a la información provista por el INEGI a través de la Encuesta intercensal 2015, se observa que los diagnósticos antes mencionados no se ajustan a la situación sociolingüística particular de cada comunidad, pues el número de hablantes del zapoteco de la planicie costera varía considerablemente de una población a otra. Por ejemplo, en algunos municipios más de $80 \%$ de los habitantes hablan esta variante lingüística, en cambio, en otros, poco menos de $5 \%$ de las personas hablan zapoteco. La tabla siguiente muestra esta información detalladamente.

Tabla 1: Hablantes del zapoteco de la planicie costera de 3 años y más por municipios

\begin{tabular}{|c|c|c|c|c|c|c|}
\hline \multirow{3}{*}{ Municipio } & \multirow{3}{*}{$\begin{array}{l}\text { Población } \\
\text { de } 3 \text { años y } \\
\text { más }\end{array}$} & \multicolumn{5}{|c|}{ Población de 3 años y más que habla zapoteco } \\
\hline & & \multirow[b]{2}{*}{$\%$} & \multirow[b]{2}{*}{ Total } & \multicolumn{3}{|c|}{ Condición de habla española } \\
\hline & & & & $\begin{array}{l}\text { Habla } \\
\text { español }\end{array}$ & $\begin{array}{c}\text { No habla } \\
\text { español }\end{array}$ & No especificó \\
\hline Asunción Ixtaltepec & 14488 & 45.6 & 6607 & 6389 & 132 & 92 \\
\hline Ciudad Ixtepec & 27378 & 21.1 & 5777 & 5638 & 23 & 116 \\
\hline Chahuites & 10753 & 4.8 & 516 & 482 & 0 & 34 \\
\hline El Espinal & 8222 & 35.6 & 2927 & 2895 & 12 & 20 \\
\hline $\begin{array}{l}\text { Juchitán de } \\
\text { Zaragoza }\end{array}$ & 92895 & 57.5 & $\begin{array}{c}53 \\
415\end{array}$ & 50157 & 2938 & 320 \\
\hline $\begin{array}{l}\text { Magdalena } \\
\text { Tlacotepec }\end{array}$ & 1181 & 22.8 & 269 & 266 & 0 & 3 \\
\hline Reforma de Pineda & 2638 & 2.5 & 65 & 64 & 1 & - \\
\hline Salina Cruz & 84788 & 5.5 & 4663 & 4355 & 0 & 280 \\
\hline
\end{tabular}




\begin{tabular}{|c|c|c|c|c|c|c|}
\hline \multirow{3}{*}{ Municipio } & \multirow{3}{*}{$\begin{array}{l}\text { Población } \\
\text { de } 3 \text { años y } \\
\text { más }\end{array}$} & \multicolumn{5}{|c|}{ Población de 3 años y más que habla zapoteco } \\
\hline & & \multirow[b]{2}{*}{$\%$} & \multirow[b]{2}{*}{ Total } & \multicolumn{3}{|c|}{ Condición de habla española } \\
\hline & & & & $\begin{array}{l}\text { Habla } \\
\text { español }\end{array}$ & $\begin{array}{l}\text { No habla } \\
\text { español }\end{array}$ & No especificó \\
\hline San Blas Atempa & 17429 & 84.6 & $\begin{array}{c}14 \\
745\end{array}$ & 13064 & 1548 & 131 \\
\hline $\begin{array}{l}\text { San Francisco } \\
\text { Ixhuatán }\end{array}$ & 8507 & 10.4 & 885 & 865 & 0 & 20 \\
\hline $\begin{array}{l}\text { San Juan Guichi- } \\
\text { covi }\end{array}$ & 27983 & 73.7 & $\begin{array}{c}20 \\
623\end{array}$ & 15921 & 4640 & 62 \\
\hline $\begin{array}{l}\text { San pedro Comi- } \\
\text { tancillo }\end{array}$ & 4058 & 48.1 & 1952 & 1923 & 14 & 16 \\
\hline $\begin{array}{l}\text { San pedro Huilo- } \\
\text { tepec }\end{array}$ & 2955 & 50.6 & 1495 & 1479 & 10 & 13 \\
\hline $\begin{array}{l}\text { San Pedro Tapana- } \\
\text { tepec }\end{array}$ & 14391 & 4.0 & 576 & 544 & 0 & 32 \\
\hline $\begin{array}{l}\text { Santa María Jalapa } \\
\text { del Marques }\end{array}$ & 12955 & 5.5 & 713 & 645 & 3 & 64 \\
\hline $\begin{array}{l}\text { Santa María Mixte- } \\
\text { quilla }\end{array}$ & 4331 & 1.4 & 61 & 58 & - & 3 \\
\hline Santa María Xadani & 8269 & 94.9 & 7847 & 6105 & 1671 & 71 \\
\hline Santiago Laollaga & 3197 & 15.8 & 505 & 495 & 3 & 7 \\
\hline $\begin{array}{l}\text { Santo Domingo } \\
\text { Chihuitán }\end{array}$ & 1432 & 7.1 & 102 & 96 & 5 & 1 \\
\hline $\begin{array}{l}\text { Santo Domingo } \\
\text { Ingenio }\end{array}$ & 7636 & 5.8 & 443 & 356 & 2 & 85 \\
\hline $\begin{array}{l}\text { Santo Domingo } \\
\text { Tehuantepec }\end{array}$ & 61431 & 7.5 & 4607 & 4285 & 18 & 304 \\
\hline $\begin{array}{l}\text { Santo Domingo } \\
\text { Zanatepec }\end{array}$ & 11525 & 1.5 & 174 & 156 & - & 18 \\
\hline Unión Hidalgo & 14703 & 56.3 & 8278 & 7972 & 199 & 99 \\
\hline
\end{tabular}

Nota. Con información del INEGI (2015).

Como se constata en la Tabla 1, el proceso de desplazamiento del zapoteco se desarrolla distintamente en cada municipio. En Reforma de Pineda, Santa María Mixtequilla y Santo Domingo Zanatepec el zapoteco está prácticamente extinto, en contraste, en San Blas Atempa y Santa María Xadani la lengua presenta una alta vitalidad. A raíz de esto, se estimó que era poco probable que los diagnósticos antes mencionados fueran aplicables al caso de Juchitán. 


\subsection{Desplazamiento del zapoteco en Juchitán}

A pesar de que no existe un diagnóstico del estado actual del desplazamiento del zapoteco en Juchitán; es posible tener un panorama general de esta problemática con la ayuda de distintas fuentes.

En una investigación realizada por Saynes-Vázquez (2002: 85-91), se indica que el proceso de desplazamiento en el municipio de Juchitán comenzó entre 1950 y 1970, pues fue en ese periodo donde los hablantes monolingües del español aumentaron, mientras que los monolingües del zapoteco disminuyeron; asimismo, la población se volvió mayoritariamente bilingüe. Esta autora identifica cinco tipos de hablantes: hablante bilingüe con más dominio en zapoteco, hablante bilingüe con más dominio en español, hablante bilingüe con un domino balanceado en ambas lenguas, hablante pasivo del zapoteco y semi-hablante del zapoteco.

En otro estudio elaborado por Augsburger (2004: 46-48), se señala que en el año 2000, los hablantes del zapoteco en dicho municipio representaban $70 \%$ de la población, de los cuales solo $9 \%$ eran monolingües. De forma más precisa, Augsburger menciona que $87 \%$ de los habitantes de 50 años y más eran hablantes del zapoteco, mientras que $47 \%$ de los niños entre 5 y 9 años hablaban la lengua.

A través de información censal brindada por el INEGI, se observa que de 1990 a 2010 la proporción de hablantes del zapoteco disminuyó 9\% en la localidad de Juchitán, especialmente en los hablantes monolingües, quienes mostraron una reducción de $30.7 \%$ (véase tabla 2).

Tabla 2: Hablantes de zapoteco de 5 años y más de 1990 a 2010

\begin{tabular}{cccccc}
\hline \multirow{2}{*}{ Censo } & \multirow{2}{*}{$\begin{array}{c}\text { Población } \\
\text { total }\end{array}$} & \multicolumn{3}{c}{ Población de 5 años y más que habla zapoteco } \\
\cline { 3 - 6 } & & \multirow{2}{*}{$*$} & Total & \multicolumn{2}{c}{ Condición de habla española } \\
\cline { 5 - 6 } & & & & No habla español & Habla español \\
\hline 1990 & 53666 & 65.92 & 35381 & 3772 & 31609 \\
1995 & 62065 & 65.26 & 40508 & 3537 & 36931 \\
2000 & 64642 & 63.65 & 41128 & 4181 & 36659 \\
2005 & 70714 & 59.70 & 42218 & 2799 & 39023 \\
2010 & 74825 & 57.48 & 43014 & 2614 & 39946 \\
\hline
\end{tabular}

Nota. Con Información del INEGI (2010).

Gracias a los datos reportados del Censo de Población y Vivienda 2010 (INEGI), se identificó la concentración y distribución de los hablantes del zapoteco en la comunidad (véase Figura 3), con lo cual se conoció que esta población transita de un bilingüismo a un mayor monolingüismo en español. 


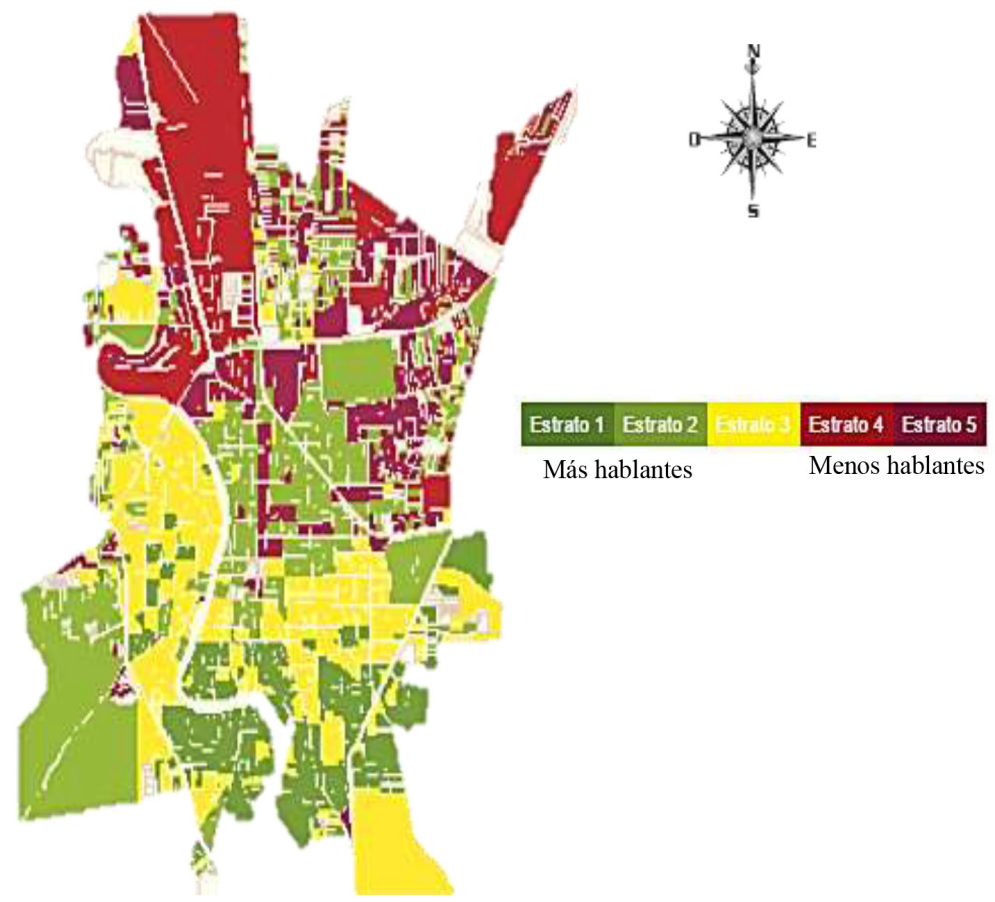

Figura 3: Distribución de los hablantes del zapoteco

Nota. Elaborado por el autor con Estratificador, INEGI. Para realizar este mapa se analizaron las siguientes variables: a) hablantes de la lengua indígena de 3 años y más, b) hablantes bilingües de la lengua indígena y del español de tres años y más, c) hablantes monolingües de la lengua indígena de tres años y más.

Como se ilustra en la Figura 3, los hablantes del zapoteco ocupan principalmente algunas zonas del centro y sur de la población, las cuales han sido consideradas barrios tradicionales con condiciones socioeconómicas desfavorables, por el contrario, en la zona norte, hacia donde la población se ha extendido, la presencia de los hablantes del zapoteco es mínima.

Finalmente, Augsburger (2004) y Saynes-Vázquez (2002) coinciden que la causa principal del desplazamiento del zapoteco es el cese de su transmisión intergeneracional en las familias zapotecas. Asimismo, en 2017 el gobierno municipal de Juchitán realizó un censo en las escuelas primarias públicas de la localidad e identificó solo a 918 niños hablantes de zapoteco de un total de 7415 niños (Diidxazá Xtinu, s.f.).

\section{Ecología de presiones}

A través de la literatura del contacto de lenguas, se suele hacer una analogía de las comunidades lingüísticas con las ecologías biológicas, pues de esta forma es posible comparar la lucha y supervivencia de las especies con el conflicto y preservación de las lenguas; por tal motivo, se suele emplear el término ecología lingüística para referirse 
a una comunidad lingüística, en cuyo interior exista un conflicto lingüístico (BastardasBoada 2014: 143-144).

Al igual que en una ecología biológica cada elemento es clave para mantener una estabilidad en el entorno y lograr una relación armónica entre las especies, en una ecología lingüística se requiere una relación simétrica de poder entre las lenguas para que su vitalidad no se vea amenazada; pero en un conflicto lingüístico, esta relación siempre es asimétrica. Cabe enfatizar que cuando una lengua se encuentra en peligro de extinción, son sus hablantes quienes están experimentando condiciones inequitativas de poder.

Al respecto, Terborg y García Landa (2011) comentan que "la persona o el grupo que esté en posesión del poder puede modificar el estado del mundo a su conveniencia [...] Entonces, el poder es de quien menos presión sienta” (p. 34). Desde este punto de vista, la presión es entendida como:

Es la que un individuo o grupo siente para actuar de una manera determinada o, en su caso, para evitar algún acto. Se considera la acción humana siempre como el producto de alguna presión. Así toda acción humana se origina a partir de alguna presión (Terborg y García Landa 2011, p. 36).

Por ello, estos autores proponen hablar de una ecología de presiones (ЕP) para explicar explícitamente las presiones que intervienen en las relaciones de poder dentro la ecología lingüística, las cuales influyen positiva o negativamente en los hablantes para que realicen acciones a favor o en contra de la vitalidad de sus lenguas. Por ejemplo, si las presiones de los hablantes $\mathrm{L}_{1}$ y de los hablantes $\mathrm{L}_{2}$ están en armonía, ambos grupos pueden mantener y procurar la vitalidad de sus lenguas; pero si los hablantes $\mathrm{L}_{2}$ comienzan a generar mayor presión hacia los hablantes $\mathrm{L}_{1}$ para imponer la $\mathrm{L}_{2}$ y restringir el uso de la $L_{1}$, este equilibro se rompe y se desencadena el proceso de desplazamiento de la $L_{1}$. Debido a esto, se vuelve imperativo identificar los orígenes de las presiones y analizar su repercusión en el desplazamiento lingüístico.

\subsection{Orígenes de las presiones}

De acuerdo con Terborg y García Landa (2011), el origen de la presión es 'el interés en algo'. Las presiones son pues productos de nuestros intereses, o sea, del tipo de objetivos (individuales, colectivos, inmediatos o permanentes) que tengamos con respecto a nuestra lengua y a la de los otros, los cuales suelen estar motivados por las necesidades, las ideologías, las creencias, los valores y las emociones asociadas con cada una de las lenguas. Por ello, no es de extrañarse que nuestros intereses entren en conflicto con los de los demás.

Asimismo, las presiones son causadas por los niveles de competencia comunicativa que hayamos desarrollado en las lenguas, dado que de esto depende nuestro poder de acción comunicativa en un determinado sistema lingüístico. La competencia comunicativa es por tanto nuestra capacidad de comunicarnos de manera eficaz y adecuada en la comunidad, esto implica que podamos respetar un conjunto de reglas que incluye tanto las de la gramática y los otros niveles de la descripción lingüística (léxico, fonética, semántica) como las reglas de uso de la lengua (Instituto Virtual Cervantes, s.f., párr. 1) (cf. Hymes 1972). 
Las presiones también pueden derivar del estado del mundo, contexto social, que limita y condiciona nuestras acciones, reorientando y redefiniendo las presiones, a su vez, nuestras acciones también lo modifican. El estado del mundo es determinante en el tipo de relaciones de poder entre los hablantes, ya que a veces este puede ser conveniente para algunas personas y, al mismo tiempo, ser totalmente inconveniente para otras (Terborg y García Landa 2011).

Si bien las repercusiones de las diferentes presiones en el proceso del desplazamiento lingüístico se pueden manifestar en diferentes acciones y circunstancias, es en la interacción en donde se expresan claramente; puesto que en entornos bilingües cada evento comunicativo implica una negociación del código lingüístico para establecer una determinada lengua como medio de comunicación. Entre más veces los interlocutores elijan una lengua, promueven su mantenimiento; de lo contrario, la lengua cae en desuso generándose su extinción.

\subsection{Presiones en la interacción}

Una elección de lengua es definida como la acción que hacen los hablantes cuando deciden en que lengua conducir una conversación (Backus y Eversteijn 2004: 1408); no obstante, esta es en principio un acto individual que puede ser compartida o no entre los interlocutores. Auer (1995: 127-132) refiere que los hablantes tienen una tendencia para usar una lengua en particular a la que denomina lengua preferente, ya sea que dicha tendencia sea motivada por una alta o baja competencia en una de las lenguas involucradas o porque está influenciada por cuestiones políticas, sociales o simplemente personales.

Entonces, ¿qué determina elegir una u otra lengua entre individuos con distinta preferencia lingüística en una interacción comunicativa? Para dar respuesta a esta interrogante, se deben seguir los siguientes pasos: 1) definir las presiones en la interacción; 2) identificar las opciones de elección lingüística que dispongan los hablantes; 3) analizar la opción lingüística que mejor satisfaga dichas presiones.

Terborg (2006, párrs. 65-69) comenta que los hablantes de las lenguas en contacto buscan consensuadamente contar con la mejor opción lingüística que les permita lograr el éxito comunicativo, visto de otra forma, los hablantes sienten una presión constante para evitar el fracaso en alguno de los siguientes niveles:

a) El mensaje no es inteligible o es parcialmente incomprensible.

b) El mensaje es comprensible para todos los participantes, pero no es aceptado por todos.

En circunstancias de relaciones inequitativas de poder, no siempre hay una negoción del código lingüístico, pues el grupo dominante impone su lengua en la comunidad lingüística. Cuando un grupo tiene más poder, puede rechazar y discriminar las características lingüísticas, étnicas y culturales del grupo menos poderoso. En una situación ideal, cualquier lengua debería tener las mismas posibilidades de ser aceptada como medio de comunicación, pero en la realidad, los hablantes que sienta mayor presión tendrán que hacer más concesiones para aceptar una lengua en particular.

Si las condiciones permiten una negociación del código, se amplían las opciones lingüísticas para los hablantes, que en muchos casos de bilingüismo social es posible 
identificar al menos tres opciones lingüísticas: código en $\mathrm{L}_{1}$ monolingüe, código en $\mathrm{L}_{2}$ monolingüe o un código mixto entre $\mathrm{L}_{1}$ y $\mathrm{L}_{2}$ (Backus y Eversteijn 2002; Mahootian 2005). ${ }^{5}$

El establecimiento de un determinado código como la elección de lingüística preferente depende esencialmente de tres factores: el grado de competencia comunicativa que los hablantes tengan en las lenguas, sus intereses y las relaciones de poder que exista entre ellos.

Por una parte, la elección de un código está motivada por el tipo de relación interpersonal que tengan los hablantes, sus identidades, la historia de vida que compartan, las convenciones culturales y sociales que han establecido para la interacción y, sobre todo, si tienen un interés mutuo para lograr el éxito comunicativo. Por otra parte, el código lingüístico debe cumplir ciertos requisitos como hacer que la atención de los interlocutores esté dirigida a pocos niveles del sistema lingüístico, más entre lo pragmático y semántico, y permitirles compartir la mayor cantidad de conocimiento posible, esto es, los hablantes tienen que poseer un alto grado de automatización en dicho sistema lingüístico. De acuerdo con la EP, la opción lingüística que mejor satisfaga tales criterios será considerada la facilidad compartida (FC) (Terborg 2006; Terborg y García Landa 2011, 2014).

$\mathrm{La}$ FC se entiende como una herramienta para la cooperación entre los distintos interlocutores con el fin de lograr el éxito comunicativo y hacer que las presiones se pongan en equilibrio durante el desarrollo de la interacción. No obstante, la FC no es estática, por el contrario, es dinámica y susceptible al cambio. Solo basta un hablante con características lingüísticas distintas para que la negociación del código vuelva a comenzar. Mientras más heterogéneo y grande sea el número de participantes en una interacción, son más las opciones lingüísticas en disputa y más alta es la intensidad de la negociación del código. En esta negociación, el código lingüístico que resulte ser el elegido, es decir, el que mayor capacidad de acción brinde a los hablantes, será considerado, además, la máxima facilidad compartida (MFC) (Terborg 2006, 2016; Terborg y García Landa 2011, 2014).

En situaciones de desplazamiento lingüístico es posible distinguir de manera más contundente los cambios de la FC entre los distintos grupos generacionales. Es común que entre los adultos mayores la FC sea la lengua minoritaria, en tanto que en los niños la FC suele ser la lengua mayoritaria; en las generaciones intermedias un código mixto puede desempeñarse como la FC.

En dicho contexto, el establecimiento de la lengua local como FC en pocas o muchas redes sociales está condicionado por la etapa en el proceso de desplazamiento lingüístico en que se encuentre, pues de esto dependerá la competencia comunicativa de sus hablantes, es decir, entre más avanzado sea el proceso de desplazamiento lingüístico, menor es la competencia comunicativa de los hablantes y, por ende, son menores las posibilidades que tiene de establecerse como la FC.

Para identificar el código lingüístico que se desempeña como la MFC en la comunidad, basta con sumar de las distintas FCS de cada red social; asimismo, la MFC se distingue de las otras opciones lingüísticas porque genera una presión constante entre las diferentes redes sociales para alinearlos lingüísticamente, fomentando así patrones repetitivos de elección de lengua que ayudan a su consolidación como la elección de lengua preferente.

\footnotetext{
${ }^{5} \mathrm{Si}$ un hablante escoge el código mixto $\mathrm{L}_{1}-\mathrm{L}_{2}$, este le permite hacer alternancia de lenguas o cambios de código.
} 


\subsection{Aplicación al análisis del desplazamiento del zapoteco}

Para fines de este estudio, se buscó hacer un diagnóstico del estado de desplazamiento del zapoteco en la comunidad de Juchitán a partir de evaluar si existen presiones que permitan que esta lengua se establezca como la FC entre los distintos grupos generacionales. Para ello, se analiza el tipo de bilingüismo social presente en la comunidad mediante la identificación del grado de competencia comunicativa tanto en zapoteco como en español de los habitantes. Con esto, se busca observar explícitamente la MFC, así como la evolución de la transmisión intergeneracional de ambas lenguas.

\section{Metodología}

\subsection{Variables}

Las variables de investigación que se establecieron fueron: grupos de edad y competencia comunicativa, las cuales son descritas en la Tabla siguiente.

Tabla 3: Variables de investigación

\begin{tabular}{|c|c|c|}
\hline Variables & Categorías & Observaciones \\
\hline \multirow[t]{4}{*}{$\begin{array}{l}\text { Competencia } \\
\text { comunicativa }\end{array}$} & Habla bien & $\begin{array}{l}\text { Tiene un alto grado de fluidez en la lengua y muestra } \\
\text { complejidad en su discurso; también utiliza le } \\
\text { lengua en diversas prácticas discursivas y ámbitos } \\
\text { sociolingüísticos. }\end{array}$ \\
\hline & Habla poco & $\begin{array}{l}\text { Presenta una baja fluidez en la lengua, tiene un cierto } \\
\text { grado de desconocimiento léxico y no muestra } \\
\text { una complejidad en el discurso; además, utiliza la } \\
\text { lengua principalmente en ámbitos privados. }\end{array}$ \\
\hline & Solo entiende & $\begin{array}{l}\text { Comprende el mensaje de su interlocutor sin } \\
\text { dificultad, pero no presenta producción oral, salvo } \\
\text { ocasionalmente producción léxica o de frases } \\
\text { ritualizadas. }\end{array}$ \\
\hline & No habla ni entiende & $\begin{array}{l}\text { Puede recordar algunas palabras y frases ritualizadas } \\
\text { en la lengua, pero tiene poca o ninguna competencia } \\
\text { gramatical o habilidad lingüística en ella. Esta } \\
\text { categoría se emplea de forma inversa, es decir, si } \\
\text { una persona informa que no entiende ni habla el } \\
\text { zapoteco, se considera hablante monolingüe del } \\
\text { español y viceversa. }\end{array}$ \\
\hline \multirow[t]{5}{*}{ Grupos de edad } & Niños & Entre 3 y 11 años \\
\hline & Adolescentes & Entre 12 y 19 años \\
\hline & Jóvenes adultos & Entre 20 y 39 años \\
\hline & Adultos maduros & Entre 40 y 59 años \\
\hline & Adultos mayores & De 60 años y más \\
\hline
\end{tabular}




\subsection{Recolección de datos}

Se realizó una encuesta por medio de un cuestionario de corte sociolingüístico aplicado de manera personal (cara a cara) a una muestra de la población de Juchitán. La muestra se conformó por 382 personas de un total de 74825 habitantes, esta estimación se obtuvo mediante la fórmula para calcular el tamaño de la muestra para la descripción de variables cualitativas en una población finita: ${ }^{6}$

$$
\mathrm{n}=\frac{\mathrm{N} \cdot \mathrm{p} \cdot \mathrm{q} \cdot(\mathrm{Z} \alpha / 2)^{2}}{(\mathrm{~N}-1) \cdot(\mathrm{E})^{2}+\mathrm{p} \cdot \mathrm{q} \cdot(\mathrm{Z} \alpha / 2)^{2}}
$$

La técnica de muestreo empleada fue aleatoria estratificada proporcional, la cual consistió primero en dividir a la población en estratos de edad y género, para ello, se obtuvo el número de individuos que conforman cada estrato; segundo, se calculó la proporción de cada estrato con respecto a la población. Esto se tomó como referencia para distribuir proporcionalmente a los sujetos de la muestra (véase Tabla 4). ${ }^{7}$

Tabla 4: Estratos por grupos de edad y género

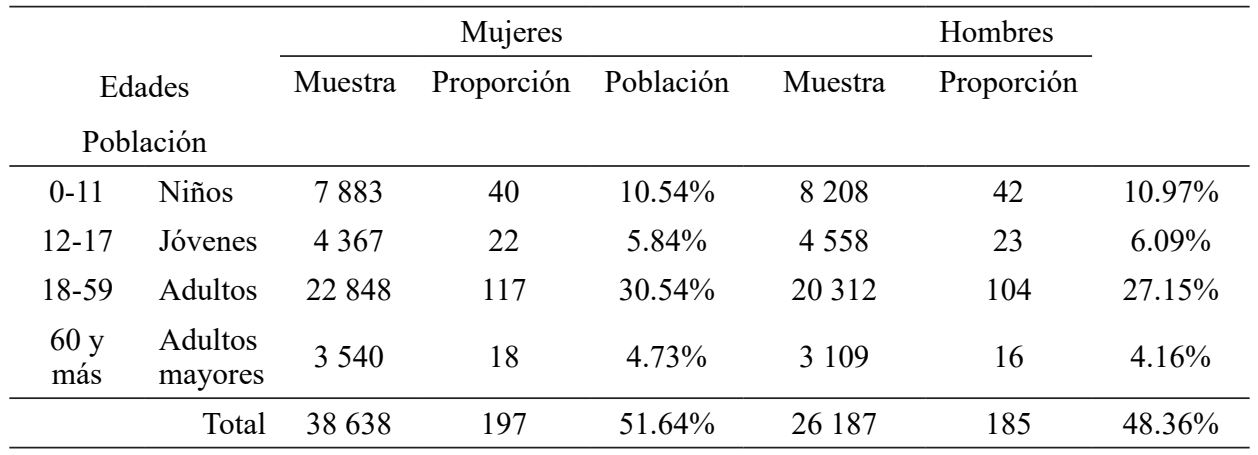

Nota. Con información de INEGI (2010).

${ }^{6} n$ representa el tamaño de la muestra; $z \alpha / 2$ es el valor crítico del grado de confianza establecido, que suele ser: 1.96 (95\%); $E$ es el error estándar, usualmente: $\pm 5 \%$ de proporción de casos (precisión absoluta); $N$ corresponde al tamaño de la población finita: $74825 ; p$ es la proporción de resultados positivos de la variable en la población: $0.5 ; q$ representa la proporción de resultados negativos de la variable en la población ( $\mathrm{q}=1-\mathrm{p})$ (Miot 2011: 275).

${ }^{7}$ Una muestra probabilística estratificada proporcional es un tipo de muestreo en el cual la población se divide en segmentos (estratos) y se selecciona una muestra para cada segmento. La proporcionalidad se refiere a que el tamaño de cada estrato de la muestra es proporcional al tamaño del estrato de la población real. Los elementos muestrales de una muestra probabilística siempre se eligen aleatoriamente para asegurarse de que cada elemento tenga la misma probabilidad de ser seleccionado. Este tipo de técnica de muestro permite plantear inferencias sobre los parámetros poblacionales reales, a partir de estadísticos de niveles de confianza y márgenes de error previamente establecidos por el investigador. Dicho de otro modo, permite realizar generalizaciones desde los resultados obtenidos a través de la muestra hacia el conjunto del universo poblacional (Grasso 2006: 87-92). 
Finalmente, la muestra presentada fue resultado de la aplicación de 382 cuestionarios a 197 mujeres y 185 hombres. Las edades de los encuestados oscilaron entre los 3 y 86 años. Además, se procuró contar con sujetos pertenecientes a las 9 secciones (barrios) de la localidad de Juchitán, quienes en su mayoría fueron encuestados en sus domicilios particulares y en algunos casos en lugares públicos, como parques. En el caso de los niños menores de 10 años, fueron los padres o tutores quienes proporcionaron la información correspondiente. La aplicación del cuestionario fue realizada entre finales de 2015 y principios de 2016 con el apoyo de un hablante bilingüe zapoteco-español de la comunidad.

\section{Análisis y resultados}

\subsection{Competencia comunicativa}

La identificación del grado de competencia comunicativa en zapoteco (LZ) y en español (LE) de los sujetos de la muestra se realizó con base en las respuestas proporcionadas a las siguientes preguntas: a) ¿cómo considera que habla el español? y b) ¿cómo considera que habla el zapoteco? Las opciones de respuesta, en el orden en que se mencionaron, fueron: 1) hablo bien, 2) hablo poco, 3) solo entiendo y 4) no lo hablo ni lo entiendo. De igual forma, a los encuestados se les solicitó que justificaran sus respuestas con ejemplos sobre el uso de la lengua y su preferencia lingüística. La Figura 4 muestra los niveles de competencia comunicativa de los participantes en ambas lenguas.

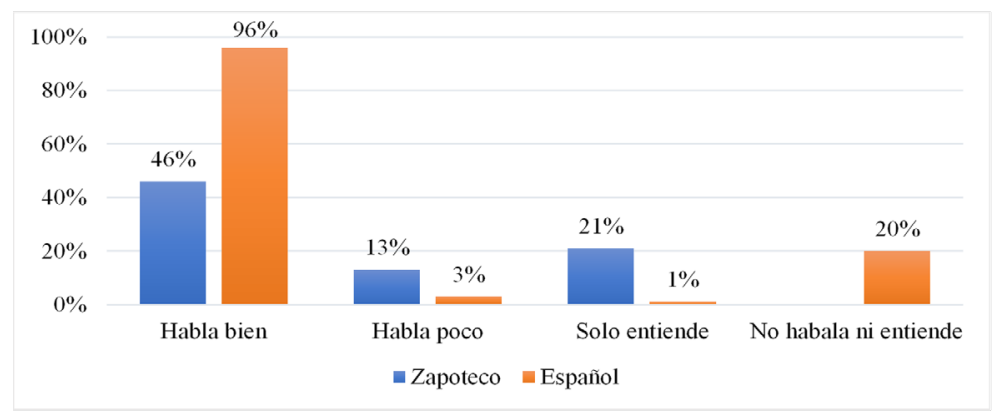

Figura 4: Competencia comunicativa en zapoteco y en español

En la Figura 4 se observa que prácticamente todos los sujetos de la muestra han adquirido una alta competencia en la LE, sin embargo, ha desarrollo pocas habilidades lingüísticas en la Lz, lo que se constata en el hecho de que solo $47 \%$ consideran que hablan bien la LZ, mientras que $13 \%$ informan que la hablan poco y $21 \%$ que solo la entienden. En estos resultados se reporta solo un hablante monolingüe de la LZ, en cambio, $20 \%$ se identifican como hablantes monolingües de la LE. 


\subsection{Facilidad compartida y máxima facilidad compartida}

Posteriormente, los resultados fueron ordenados en cinco grupos de edad (niños de 3 a 11 años, adolescentes de 12 a 19 años, jóvenes adultos de 20 a 39 años, adultos maduros de 40 y 59 años y, adultos mayores de 60 años y más) y analizados con la fórmula del conocimiento percibido (CPL) (Terborg 2016: 25$): \mathrm{V}=\{[(3 \times \mathrm{B})+(2 \times \mathrm{P})+(1 \times \mathrm{E})+(0 \times \mathrm{N})] /$ $(3 \times \mathrm{T})\} \times 100$, en donde $V$ es el valor promedio del CPL, $B$ corresponde a la respuesta habla bien, $P$ a habla poco, $E$ a solo entiende, $N$ a no habla ni entiende y $T$ es el número total de casos. Con este procedimiento, se logró obtener un valor promedio por cada grupo generacional.

La Figura siguiente presenta los valores obtenidos a través de una gráfica de líneas que empieza con el grupo de adultos mayores y termina con el de los niños, pues de esta forma se puede estudiar cómo ha ido cambiando la FC intergeneracionalmente, así como determinar la lengua que se ha establecido como la MFC.

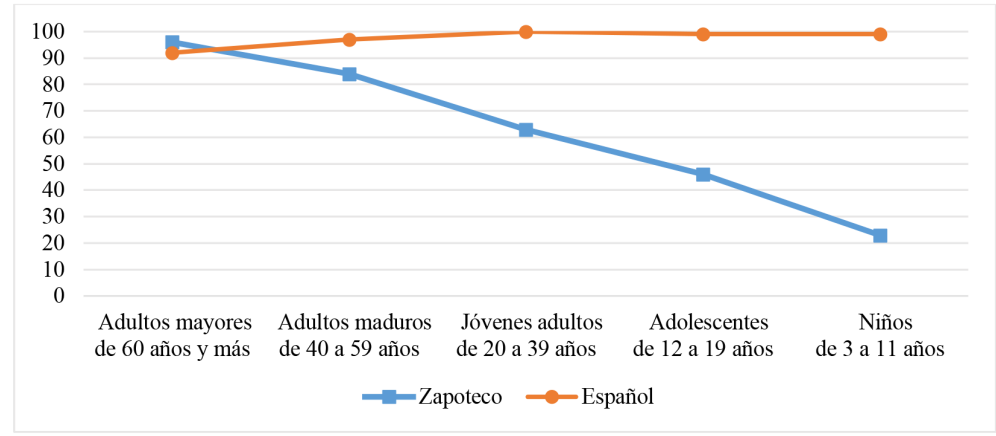

Figura 5: Conocimiento percibido del zapoteco y del español

Como se muestra en la Figura 5, la LE alcanza un valor aproximado de 100 puntos en cada grupo de etario, con excepción del grupo de adultos mayores que obtienen un valor de 92 puntos; esto se debe a que todavía hay algunas que personas que hablan poco la LE y en unos casos solo la entienden. Por tanto, la LE es la FC en la mayoría de los grupos de edad, también con altas posibilidades de serlo en los adultos mayores.

En cuanto a la LZ, los resultados varían en los diferentes grupos generacionales. En primer lugar, podemos apreciar que para los adultos mayores la LZ es la FC, pues obtienen un valor de 100 puntos, esto significa que todos son hablantes fluidos en la lengua; en cambio, en las generaciones subsecuentes el valor reportado desciende aproximadamente 20 puntos.

Los adultos maduros alcanzan un valor de 84 puntos; lo que significa que cuentan con las capacidades lingüísticas para que la LZ se establezca como la FC. Los jóvenes adultos, por su parte, reportan un valor de 63 puntos; en esta generación aún existen algunos hablantes fluidos en la LZ, pero restringen su uso al ámbito familiar, esta situación reduce las posibilidades de que la LZ se defina como la FC. En el caso de los adolescentes, este grupo obtiene un valor de 46 puntos, es decir, aproximadamente la mitad de ellos habla poco la LZ o, solo la entiende; en este caso la LZ ya no tiene posibilidades de desempeñarse 


\section{GUERRA-MEJÍA - Evaluación DEL ESTAdo DE DESPLAZAMiENTO...}

como la FC. De forma similar, los niños alcanzan un valor de 23 puntos, lo que implica que prácticamente, muy pocos solo entienden la LZ.

Con base en estos resultados, se determina que la LE es la MFC, pues es la lengua que permite a los distintos grupos generacionales una mayor capacidad de acción en la interacción; además, es la lengua que los alinea lingüísticamente.

\subsection{Grado de desplazamiento lingüístico}

Para la evaluación del grado de desplazamiento de la LZ, se empleó la clasificación del proceso de desplazamiento de una lengua indígena (LI) por la LE (cf. Terborg 2016). Esta clasificación nos permite visualizar las etepas del desarrollo del desplazamiento de la LI entre los distintos grupos de generacionales (grupo A de 3 a 19 años, grupo в de 20 a 39 años y grupo c de 40 años y más). La Figura siguiente ilustra las posibles etapas de este proceso.

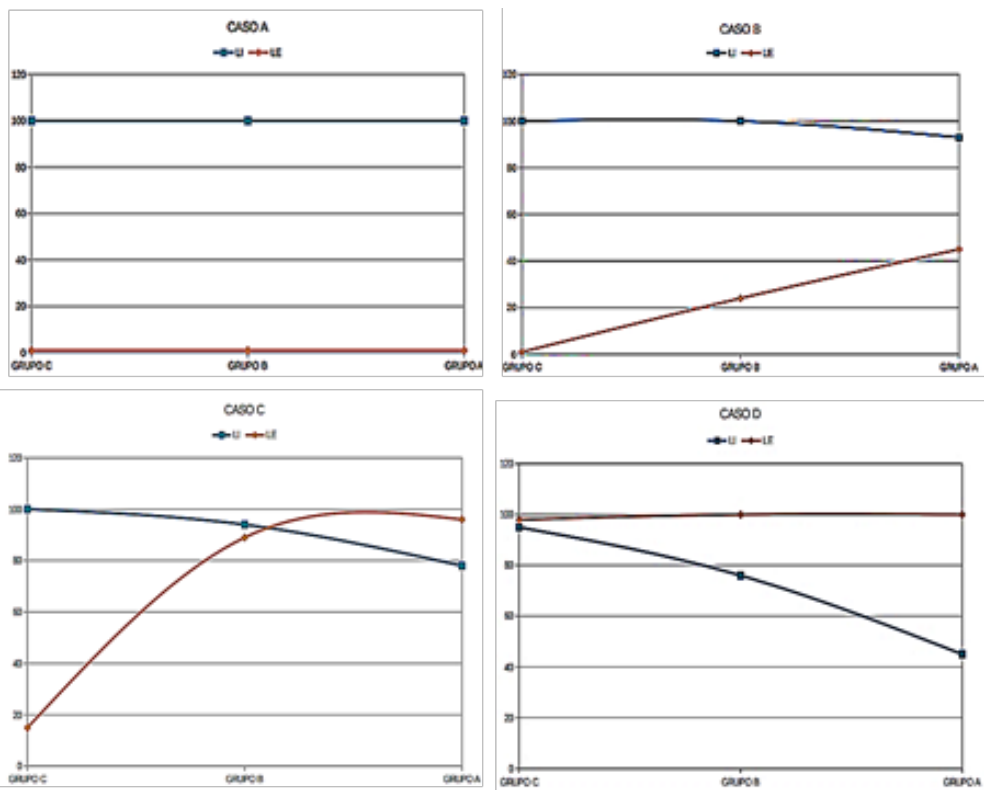

Figura 6: Clasificación del proceso de desplazamiento de una LI por la LE Nota. Adaptado de Terborg (2015 en Guerra-Mejía 2017: 62).

- La Figura 6 muestra cuatro posibles casos de desplazamiento lingüístico:

- Caso A: etapa de contacto. En esta fase la población ha desarrollado una mínima o nula competencia comunicativa en la LE, por lo que la LI es la FC en todos los grupos generacionales y, por consiguiente, la MFC en la comunidad.

- Caso в: etapa de inicio, desplazamiento incipiente. La población más joven ha comenzado a desarrollar una alta competencia comunicativa en la LE, no obstante, esto no representa un riesgo para LI de mentenerse como la FC y MFC. 
- Caso C: etapa de transisión, desplazamiento moderado. La LE ha pasado a ser la FC en niños y adolescentes, mientras que la LI se mantiene como la FC en los adultos mayores; entre los adultos la FC no es tangible, un código mixto LI-LE puede establecerse como la FC. En esta fase la MFC no es siempre clara.

- Caso D: Etapa de consolidación, desplazamiento avanzado. La LI ha sido desplazada intergeneracional por la LE. En los adultos mayores tanto la LI como la LE pueden desempeñarse como la FC, pero en el resto de la población solo la LE tiene posibilidades de ser la FC. En esta fase la LE se ha establecido como la MFC.

En estas etapas el grado de inclinación de la pendiente del conocimiento de la LI indica si el desplazamiento se desarrolla de forma lenta o acelerada. Mientras más inclinada sea la pendiente, mayor es la velocidad del desplazamiento.

De acuerdo con esta clasificación, se determina que la Lz presenta un grado avanzado de desplazamiento lingüístico, que se desarrolla de forma acelerada, pues los datos reportados en la Figura 5 corresponden a un caso de tipo D.

\section{Conclusiones}

Como conclusión, se establece que el zapoteco presenta un estado de desplazamiento lingüístico avanzado en la localidad de Juchitán, como consecuencia de una disminución acelerada de su transmisión intergeneracional. Esto indica que este proceso se encuentra en una etapa de consolidación (cf. Figura 6).

Dicho estado de desplazamiento lingüístico repercute en contra del uso del zapoteco restringiendo sus posibilidades de desempeñarse como la facilidad compartida entre la población, únicamente los adultos mayores y los adultos maduros tienen las capacidades lingüísticas necesarias para establecer esta lengua como la facilidad compartida. En contraste, el español se ha establecido como la elección de lengua preferente y, por ende, como la máxima facilidad compartida. Este debilitamiento en las presiones comunicativas del zapoteco puede ser una de las causas que propician que las familias dejen de transmitir la lengua.

Los resultados de estudio también muestran que la comunidad de Juchitán presenta un bilingüismo social con predominancia en español, lo que posiciona al zapoteco en la tercera de cinco etapas del proceso de desplazamiento lingüístico propuesto por Batibo (2005) (cf. sección 2). Esto se debe a que la gran mayoría de la población ha desarrollado una alta competencia comunicativa en el español, salvo en algunos casos entre las personas mayores de 60 años que solo lo entienden; por el contrario, aproximadamente solo la mitad de la población es hablante fluido del zapoteco y $30 \%$ son hablantes semifluidos y receptivos de la lengua, en su mayoría jóvenes adultos, adolescente y niños.

Estas diferencias en los niveles de competencia comunicativa en zapoteco entre los distintos grupos generacionales revelan que la disminución de la transmisión intergeneracional comenzó a partir de la generación de los maduros mayores y se aceleró en la generación de los adultos maduros, lo cual se ajusta con los datos reportados por Saynes-Vázquez (2002), quien señala que el proceso de desplazamiento del zapoteco en municipio de Juchitán comenzó entre 1950 y 1970. 
Por otra parte, a diferencia del gobierno municipal de Juchitán que identificó a 923 niños hablantes del zapoteco en la comunidad (Diidxazá Xtinu, s.f.), en esta investigación no se detectó a ningún niño hablante fluido en zapoteco; no obstante, ambos reportes refieren una disminución altamente significativa de hablantes del zapoteco en esta generación.

Con base en la información brindada en este estudio, se advierte que es muy probable que en la siguiente generación de niños la transmisión intergeneracional del zapoteco se interrumpirá por completo. Si está tendencia sigue su curso, en dos generaciones el zapoteco se habrá desplazado funcionalmente, es decir, los hablantes fluidos en zapoteco serán una minoría que no representarán una presión comunicativa en la comunidad, por tanto, las posibilidades de que el zapoteco sea empleado como medio de comunicación serán prácticamente nulas. Asimismo, se espera que entre cuatro y cinco generaciones aproximadamente el proceso de desplazamiento del zapoteco haya concluido, esto es, no quedarán hablantes fluidos ni semifluidos, lo que provocará la extinción de la lengua en la comunidad.

La evaluación del estado de desplazamiento del zapoteco presentado aquí indica un mayor grado de peligro de extinción que los establecidos en los diagnósticos siguientes:

- UNESCO (2010): vitalidad vulnerable.

- INALI (2012): riesgo medio de desaparición.

- Ethnologue (2020): estatus en desarrollo.

Sin embargo, cabe mencionar que las conclusiones de este estudio pueden estar limitadas por algún defecto en la representatividad de la muestra. Por ello, se recomienda analizar una muestra más grande y ampliamente representativa.

Como futuras líneas de investigación, sería conveniente que se realizarán estudios cualitativos sobre la representación simbólica del zapoteco en la población de Juchitán, el uso de la lengua en distintos ámbitos sociales y las políticas del lenguaje en la familia que repercuten en la transmisión de la lengua, así como desarrollar estudios sobre planificación del lenguaje que permitan implementar acciones de revitalización lingüística.

\section{Referencias}

Augsburger, Deborah (2004). Language socialization and shift in an Isthmus Zapotec community of Mexico (Tesis de doctorado en antropología). Universidad de Pennsylvania. Repositorio institucional UPENN. https://repository.upenn.edu/dissertations/AAI3125780

Auer, Peter (1995). The pragmatics of codeswitching: A sequential approach. En Lesley Milroy y Pieter Muysken (eds.), One Speaker, Two Languages: Cross-disciplinary perspectives on codeswitching, pp. 115-135. Cambridge: Cambridge University Press.

Backus, Ad y Eversteijn, Nadia (2004). Pragmatic functions and their outcomes: Language choice, codeswitching, and non-switching. En Anxo M. Lorenzo Suárez; Fernando Ramallo y Xoán Paulo Rodríguez Yáñez (eds.), Bilingual socialization and bilingual language acquisition: Proceedings from the Second International Symposium on Bilingualism [Universidad de Vigo, Galicia, España, Octubre 23-26, 2002], pp. 1392-1410. Servizo de Publicacións da Universidade de Vigo. 
Bastardas-Boada, Albert (2014). Ecología y sostenibilidad lingüística: Una aproximación desde la (socio) complejidad. En Miguel Casas Gómez (dir.) y Rocío Vela Sánchez (ed.), Eugenio Coseriu, in memoriam. XIV Jornadas de Lingüistica, pp. 143-163. Cadiz: Universidad de Cádiz, Servicio de Publicaciones.

Bastardas Boada, Albert (2016). Ecología lingüística y lenguas minoritarias: Algunas notas sobre el desarrollo del campo. En A. Fernández Planas (ed.), 53 reflexiones sobre aspectos de la fonética y otros temas de lingüística, pp. 449-458. Universidad de Barcelona.

Batibo, Herman M. (2005). Language decline and death in Africa: Causes, consequences and challenges. Multilingual Matters.

Campbell, Lyle; Muntzel, Martha C. (1989). The structural consequences of language death. En Dorian, Nancy. C. (ed.), Investigating obsolecence. Studies in Language Contraction and Death, pp. 181-196. Cambridge University Press.

Centro Virtual Cervantes (s.f.). Competencia comunicativa. Diccionario de términos clave de ELE. Consultado el 20 de Abril de 2020.

https://cvc.cervantes.es/ensenanza/biblioteca ele/diccio_ele/diccionario/competenciacomunicativa.htm

Craig, Colette Grinevald (1998). Language contact and language degeneration. En Florian Coulmas (ed.), The Handbook of Sociolinguistics, pp. 257-270. Blackwell Publishing.

Crystal, David (2000). Language death. Cambridge: Cambridge University Press.

Diidxazá Xtinu (s.f.). Consultado el 15 de mayo de 2020. https://diidxazaxtinu.com/

Eberhard, David M.; Simons, Gary F. y Fennig, Charles D. (eds.) (2020). Ethnologue: Languages of the World (20. ${ }^{a}$ ed.). SIL International. http://www.ethnologue.com.

Fasold, Ralph (1996). La sociolingüistica de la sociedad. Introducción a la sociolingüistica. Madrid: España: Visor Libros.

Fishman, Joshua A. (1967). Bilingualism with and without diglossia; Diglossia with and without bilingualism. Journal of Social Issues 23: 29-38.

Fishman, Joshua A. (1991). Reversing language shift. Multilingual Matters.

Grasso, Livio (2006). Encuestas. Elementos para su diseño y análisis. Encuentro Grupo Editor.

Grinevald, Colette; Bert, Michel (2011). Speakers and communities. En Peter K. Austin y Julia Sallabank (eds.), The Cambridge Handbook of Endangered Languages, pp. 45-65. Cambridge: Cambridge University Press.

Guerra-Mejía, Roberto (2017). El mantenimiento de una lengua indígena en un contexto urbano contemporáneo de México: El caso del diidxazá o zapoteco en Juchitán, Oaxaca (Tesis de maestría en lingüística aplicada). México: Universidad Nacional Autónoma de México. Repositorio institucional UNAM en: https://repositorio.unam.mx/contenidos/117410

Hymes, Dell (1972). On communicative competence. En Pride, J. B. \& Holmes, J. (eds.), Sociolinguistics, pp. 269-293. Penguin Education, Penguin Books Ltd. 


\section{GUERRA-MEJÍA - EvaluACión DEL ESTAdo DE DESPLAZAMIENTO...}

Instituto Nacional de Lenguas Indígenas (México) (2009). Catálogo de las lenguas indígenas nacionales: Variantes lingüísticas de México con sus autodeterminaciones y referencias geoestadísticas. INALI. Disponible en: https://site.inali.gob.mx/pdf/catalogo_lenguas_indigenas.pdf

Instituto Nacional de Lenguas Indígenas (México) (2012). México. Lenguas indígenas nacionales en riesgo de desaparición: Variantes lingüisticas por grado de riesgo. 2000 (Arnulfo Embriz Osorio y Óscar Zamora Alarcón, coords.). INALI https://site.inali.gob.mx/pdf/libro_lenguas_indigenas_nacionales_en_riesgo_de desaparicion.pdf

Instituto Nacional de Estadística y Geografía (México) (2010). Principales resultados por localidad (ITER) [base de datos en línea]. https://www.inegi.org.mx/sistemas/scitel/default?ev=5

Instituto Nacional de Estadística y Geografía (México) (2015). Encuesta Intercensal 2015. Tabulados [base de datos en línea]. https://sinegi.page.link/u1RR

Instituto Nacional de los Pueblos Indígenas (México) (2010). Catalogo de localidades indígenas 2010 [base de datos en línea]. http://www.cdi.gob.mx/localidades2010-gobmx/

Mahootian, Shahrzad (2005). Linguistic change and social meaning: Codeswitching in the media. International Journal of Bilingualis 9(3-4): 361-375.

Miguel-Velasco, Andrés Enrique; Martínez García, Karina Aidee; Pérez Pérez, Maribel y Moncada García, María del Rosario (2017). Las redes de la vivienda y el desarrollo sustentable en la centralidad de las ciudades de Oaxaca, México, 2000-2015. Estudios Demográficos y Urbanos 32(3): 515-546.

http://dx.doi.org/10.24201/edu.v32i3.1729

Miot, Hélio Amante (2011). Sample size in clinical and experimental trials. J Vasc Bras 10 (4): 275-278.

Moseley, Christopher (ed.) (2010). Atlas de las lenguas del mundo en peligro (3. ${ }^{\mathrm{a}}$ ed.) [base de datos en línea]. Ediciones UNESCO. http://www.unesco.org/culture/languages-atlas/es/atlasmap.html

Ninyoles, Rafael (1969). Conflicte lingüistic valencià. València: Col.lecció Tres i Quatre.

Rojo Sánchez, Guillermo (1981). Conducta y actitudes lingüísticas en Galicia. Revista Española de Lingüistica 11(2): 260-310.

Saynes-Vázquez, Flores Edaena (2002). Zapotec language shift and reversal in Juchitán, Mexico (Tesis de doctorado en filosofía). Universidad de Arizona. Repositorio institucional UA.

http://hdl.handle.net/10150/289854

Smith-Kocamanhhul, Joan (2003). Language choice, code-switching and language shift in Antakya, Turkey (Tesis de doctorado de filosofía en lingüística). Universidad de Canterbury. Repositorio institucional UC. http://hdl.handle.net/10092/2839

Terborg, Roland (2006). La “ecología de presiones" en el desplazamiento de las lenguas indígenas por el español. Presentación de un modelo. Forum: Qualitative Social Research 7(4). Art. 39.

http://dx.doi.org/10.17169/fqs-7.4.167

Terborg, Roland (2016). ¿Cómo clasificar el avance del desplazamiento de una lengua indígena para una adecuada planificación del lenguaje? Un primer intento de medición. UniverSOS 13: 11-35. 
Terborg, Roland y García Landa, Laura Gabriela (2011). Las presiones que causan el desplazamientomantenimiento de las lenguas indígenas. La presentación de un modelo y su aplicación. En Muerte y vitalidad de las lenguas indigenas y las presiones sobre sus hablantes, pp. 29-61. UNAM-CELE.

Terborg, Roland y García Landa, Laura Gabriela (2014). La ecología de presiones: Una herramienta para el análisis del proceso de mantenimiento-desplazamiento de lenguas desde el punto de vista de la complejidad. En Àngels Massip Bonet y Albert Bastardas Boada (eds.), Complèxica. Cervell, societat i llengua des de la transdisciplinarietat, pp. 317-344. Publicacions i Edicions de la Universitat de Barcelona.

Valiñas Coalla, Leopoldo (2019). Zapoteco del Istmo. Arqueología Mexicana: Las lenguas indígenas de México (edición especial No. 85), 78.

Zimmermann, Klaus (1999). Política del lenguaje y planificación para los pueblos amerindios: Ensayos de ecología lingüistica. Madrid, España: Iberoamerica.

Recebido: 26/9/2019

Versão revista e corrigida (1): 4/6/2020

Versão revista e corrigida (2): 6/6/2020

Aceito: 8/6//2020.

LIAMES, Campinas, SP, v. 20, 1-23, e020006, 2020 